\title{
IMPLEMENTASI BUDAYA BALI DAN KONSEP TRI HITA KARANA DI HARRIS HOTEL, SEMINYAK-BALI
}

\author{
Dinar Sukma Pramesti dan Putu Gilang Adnyani \\ Email: dinar.pramesti@pib.ac.id \\ POLITEKNIK INTERNASIONAL BALI
}

\begin{abstract}
The purpose of this study was to determine how the application of Balinese culture and the Tri HIta Karana (THK) concept at Harris Hotel Seminyak, one of the hotels in Bali. This study used a qualitative method. Informants were determined using the Purposive Sampling technique. The informant in this study was Harris Hotel Seminyak management. The types of data in this study are primary and secondary data. Data were obtained through interviews, observations and study documents.

The implementation of Balinese culture in Harris Hotel Seminyak can be seen from the Balinese traditional clothes worn by Harris staffs conductiong Balinese traditional fashion competition, Balinese decoration making competition, making penjor, displaying paintings of the hindu religious activities and Balinese people's daily activities, as well as serving Balinese traditional dishes.

The implementation of the THK concept can also be seen from the Parhyangan concept, which is giving the freedom of worship, providing some worship places, arranging offerings or canang sari in padmasana and in each section of the department, installing pelangkiran in every room, doing religious activities or odalan in Padmasana and do tirtayatra or spiritual trip to several temples in Bali and Java. The implementation of the THK concept is seen from the concept of pawongan, namely holding Sima Krama Dharma Santhi / hospitality and A day to share activities. The implementation of the THK concept can be seen from the concept of palemahan that commemorates Tumpek Uduh (a special day for plants and trees), Tumpek Kandang (a special day of animals) and Mecaru (Bhuta Yadnya) with various levels, and cleaning the beach and the area of Seminyak village.
\end{abstract}

Keywords: Balinese Culture, THK, Harris Hotel Seminyak

\section{Abstrak}

Tujuan penelitian ini untuk mengetahui bentuk penerapan budaya Bali dan konsep THK pada Harris Hotel Seminyak yang merupakan salah satu hotel yang berlokasi di Bali. Penelitian ini menggunakan metode 
kualitatif. Informan ditentukan dengan menggunakan teknik Purposive Sampling. Informan dalam penelitian ini yaitu manajemen Harris Hotel Seminyak. Jenis data yang digunakan adalah data primer dan sekunder. Data diperoleh melalui wawancara, observasi dan studi dokumen.

Adapun wujud implementasi budaya Bali di Harris Hotel Seminyak yaitu penggunaan pakaian adat Bali pada hari Kamis maupun hari-hari keagamaan, mengadakan kegiatan berupa lomba busana adat Bali, lomba membuat dekorasi Bali, membuat penjor, memajang lukisan dengan gambar aktivitas umat agama Hindu di Bali yang sedang menjalankan persembahyangan, maupun aktivitas sehari-hari serta menyajikan menu makanan khas Bali.

Wujud implementasi konsep THK dilihat dari konsep Parhyangan yaitu memberikan kebebasan beribadah, menyediakan beberapa tempat persembahyangan, menghaturkan canang sari di padmasana dan di setiap section dapartement, mengisi setiap ruangan dengan pelangkiran, melakukan piodalan di Padmasana serta melakukan tirtayatra ke beberapa Pura di Bali maupun Jawa. Wujud implementasi konsep pawongan yaitu mengadakan kegiatan Sima Krama Dharma Santhi/silaturahmi dan kegiatan $A$ day to share. Wujud implementasi konsep palemahan yaitu memperingati tumpek uduh, tumpek kendang, melaksanakan kegiatan mecaru (Bhuta Yadnya), melaksanakan kegiatan bersih-bersih pantai dan areal desa Seminyak.

Kata Kunci: Budaya Bali, THK, Harris Hotel Seminyak

\section{Pendahuluan}

Pariwisata yang dikembangkan di Bali adalah pariwisata budaya. Hal tersebut telah ditetapkan berdasarkan peraturan Daerah Provinsi Bali nomor 2 tahun 2012 tentang Kepariwisataan Budaya Bali. Kepariwisataan Budaya Bali adalah kepariwisataan yang berlandaskan kebudayaan Bali yang dijiwai oleh ajaran agama Hindu dan konsep Tri Hita Karana (THK) sebagai potensi utama dengan menggunakan kepariwisataan sebagai wahana aktualisasinya sehingga terwujud hubungan timbal balik yang dinamis antara kepariwisataan dan kebudayaan serta membuat keduanya berkembang secara sinergis, harmonis dan berkelanjutan untuk dapat memberikan kesejahteraan kepada masyarakat, kelestarian budaya dan lingkungan. 
Guna mendukung kepariwisataan Budaya Bali, Pemerintah mewajibkan akomodasi wisata, seperti halnya hotel untuk mengimplementasikan budaya Bali dan konsep Tri Hita Karana (THK). Sayangnya, hotel-hotel dengan konsep modern dan tidak menerapkan budaya Bali dan konsep THK banyak ditemui di Bali. Hal ini tentunya bertentangan dengan kepariwisataan budaya Bali dan Peraturan-peraturan lainnya seperti peraturan Daerah No. 5 Tahun 2005 (Pengaturan persyaratan arsitektur bangunan yang sesuai dengan prinsip arsitektur tradisional Bali) dan RTRWP 16 tahun 2009 (Nilai kearifan lokal Bali yang terkait dalam penataan ruang).

Ketua Yayasan THK, I Gusti Ngurah Wisnu Wardana dalam acara Malam Penganugerahan THK Tourism Awards \& Accreditation 2018 pada hari Jumat, 30 November 2018 di Gedung Ksirarnawa Art Center, Bali (Humas BAPPSIK, 2018), mengungkapkan bahwa para pelaku pariwisata ikut berpartisipasi mewujudkan pembangunan Bali yang berkelanjutan dengan mengedepankan prinsip harmoni dan keberlanjutan yang dijiwai oleh nilai-nilai religius dalam konsep THK dengan menyelenggarakan THK Awards. THK Awards merupakan ajang penghargaan bagi hotel, kantor Pemerintahan, Daerah Tujuan Wisata (DTW), Perguruan Tinggi, Sekolah (SMP/SMA/SMK), Badan CSR, dan Public Relation yang telah menerapkan konsep THK. THK adalah sebuah konsep yang menekankan tiga hubungan manusia dalam kehidupan di dunia ini. Ketiga hubungan itu meliputi hubungan dengan sesama manusia, hubungan dengan alam sekeliling, dan hubungan dengan ke Tuhan yang saling terkait satu sama lain (Wiana, 2004:141). Dengan diterapkannya konsep THK, diharapkan kelestarian budaya Bali dapat terjaga, selain itu juga dilakukan untuk menjaga keseimbangan antara makrokosmos dan mikrokosmos (alam semesta dan manusia) agar berjalan dengan selaras. 
Salah satu hotel yang ada di Bali tepatnya di daerah Seminyak, Badung, Bali yaitu Harris Hotel Seminyak. Harris Hotel Seminyak merupakan salah satu dari sekian banyak hotel yang berada di Bali yang belum terdaftar sebagai peserta THK Award. Harris Hotel Seminyak adalah hotel Harris ke 7 di Bali dan ke 15 di Indonesia dengan jaringan pengelolaan dari kantor manajemen Tauzia. Hotel ini memiliki konsep terbuka untuk semua tamu, tapi sangat cocok untuk yang berjiwa muda. Bangunan Harris Hotel Seminyak berkonsep modern dengan dekorasi yang berwarna terutama warna oranye dan hijau. Seragam para pegawainya bergaya sportif. Berdasarkan latar belakang tersebut, maka artikel ini berupaya memaparkan implementasi Budaya Bali dan konsep THK di Harris Hotel Seminyak, Bali. Tujuan penelitian ini untuk mengetahui bentuk penerapan budaya Bali dan konsep THK pada Harris Hotel Seminyak yang merupakan salah satu hotel yang berlokasi di Bali.

\section{Gambaran Harris Hotel Seminyak}

Harris Hotel Seminyak dibuka pada bulan Agustus tahun 2014 Hotel ini berlokasi di Jalan Drupadi, Seminyak-Bali. Lokasi ini sangat dekat dengan pantai Seminyak yaitu sekitar 15 menit jika ditempuh dengan berjalan kaki dan 30 menit berkendara dari Bandara Internasional Ngurah Rai. Harris Hotel Seminyak menyediakan 231 kamar. Seperti hotel bintang 4 lainnya, hotel ini juga memiliki kafe dan restoran yang menyajikan berbagai menu nasional dan internasional. Saat masuk ke hotel, para tamu disambut oleh Dino, maskot Harris Hotel Seminyak. Dino adalah simbol berupa dinosaurus, binatang yang akrab dengan berbagai umur dan kalangan, terutama anak-anak. Simbol ini mengesankan bahwa Harris hotel bergaya kasual yang aman buat keluarga. Di hotel ini tersedia ruangan Dino atau ruangan bermain untuk anak-anak. Di sampingnya tersedia kolam renang yang aman dan nyaman buat anak-anak karena 
kedalamannya rendah. Kolam renang dewasa juga tersedia dilantai atas. Para tamu bisa berenang sambil menikmati pemandangan sekitar hotel dari ketinggian.
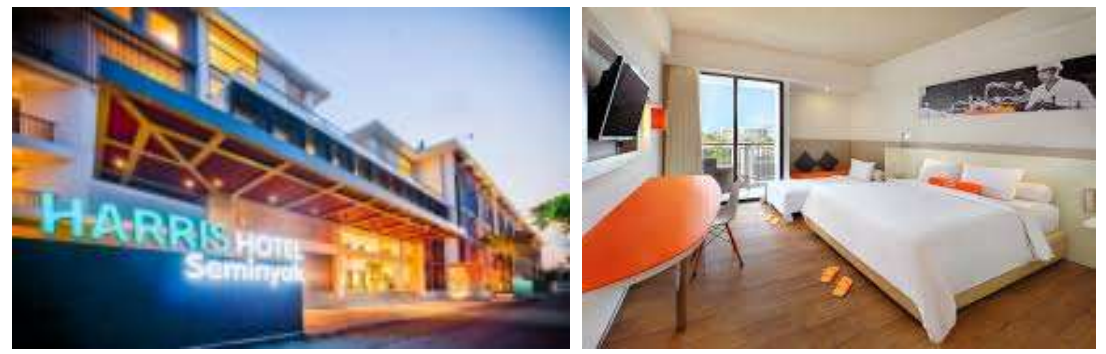

Gambar 1. Eksterior dan interior Harris Hotel Seminyak

Sumber: Manajemen Harris Hotel Seminyak

\section{Budaya Bali dan Konsep Tri Hita Karana}

Menurut Koentjaraningrat (2002), kebudayaan atau budaya didefinisikan sebagai keseluruhan dari sistem nilai, tindakan, dan hasil karya manusia dalam kehidupan masyarakat yang diperoleh melalui proses belajar. Budaya terdiri dari tujuh unsur yaitu bahasa, sistem kekerabatan dan organisasi sosial, sistem religi, mata pencaharian hidup, sistem pengetahuan, system peralatan dan teknologi serta kesenian. Budaya Bali dapat didefinisikan sebagai keseluruhan dari sistem nilai, perilaku, dan hasil karya manusia Bali yang terbentuk dari proses interaksi manusia Bali dengan lingkungannya. Kebudayaan Bali dilandasi oleh nilai-nilai yang bersumber pada ajaran agama Hindu.

Budaya Bali sesungguhnya merupakan ekspresi dari hubungan interaksi orang Bali dengan lingkungannya. Dalam kosmologi orang Bali, lingkungan dibedakan atas dua macam, yakni lingkungan sekala (nyata) dan lingkungan niskala (tidak nyata). Lingkungan sekala meliputi lingkungan sosial (masyarakat) dan lingkungan fisik (alam sekitarnya). Sedangkan lingkungan niskala merupakan lingkungan spiritual yang dihuni oleh kekuatan-kekuatan supernatural atau adikodrati yang diyakini dapat menimbulkan pengaruh positif maupun negatif terhadap kehidupan 
manusia. Ekspresi dari interaksi antara orang Bali dengan lingkungan spiritual (niskala) melahirkan sistem religi lokal atau agama Bali yang di dalamnya mencakup emosi atau sentimen keagamaan, konsepsi tentang kekuatan-kekuatan dan mahluk-mahluk gaib, upacara ritual keagamaan, fasilitas keagamaan, kelompok atau komunitas keagamaan.

Dalam perkembangan selanjutnya keberadaan religi lokal tersebut bercampur dengan unsur-unsur agama Hindu yang disebabkan oleh adanya interaksi kebudayaan pada masa lampau. Ekspresi dari interaksi antara orang Bali dengan lingkungan sosial antara lain melahirkan Basa Bali (Bahasa Bali), norma-norma, peraturan-peraturan, hukum (sima, dresta, awig-awig), pranata-pranata sosial seperti pranata kekerabatan (nyama, braya, dadia, soroh), dan pranata kemasyarakatan (sekeha, banjar, desa, gumi) dan sebagainya. Ekspresi dari interaksi orang Bali dengan lingkungan fisik antara lain melahirkan sistem pengetahuan tentang alam (seperti penanggalan sasih, pawukon, pramatamangsa), system subak, dan lain sebagainya. Orang Bali juga mengenal berbagai jenis peralatan dan teknologi yang digunakannya untuk beradaptasi dengan lingkungan fisik (Pujaastawa, 2002).

Budaya Bali juga menjunjung tinggi nilai-nilai keseimbangan dan harmonisasi yang tertuang dalam konsep THK. Tri Hita Karana atau yang disingkat dengan THK adalah bagian dari budaya Bali. THK terdiri atas tiga kata yaitu tri, artinya tiga. Hita artinya kebahagiaan atau kesejahteraan. Karana artinya sebab. Jadi THK berarti tiga komponen atau unsur yang menyebabkan kesejahteraan atau kebahagiaan. Sudarta (2008: 84) mengungkapkan ketiga komponen THK berkaitan erat antara yang satu dengan yang lainnya, meliputi hubungan yang harmonis antara manusia dengan Tuhan Yang Maha Esa (Parhyangan), hubungan yang harmonis antara manusia dengan manusia (Pawongan), dan hubungan yang harmonis antara manusia dengan alam lingkungan (Palemahan). 


\section{Metode}

Penelitian ini menggunakan metode kualitatif. Informan ditentukan dengan menggunakan teknik Purposive Sampling. Informan dalam penelitian ini yaitu manajemen Harris Hotel Seminyak. Jenis data yang digunakan adalah data primer dan sekunder. Data primer adalah data yang diperoleh langsung oleh peneliti, tanpa perantara. Data sekunder yaitu diperoleh dari sumber penelitian dokumen terkait. Teknik pengumpulan data menggunakan wawancara, observasi dan studi dokumen.

\section{Implementasi Budaya Bali dan Konsep Tri Hita Karana Pada Harris Hotel, Seminyak-Bali}

Berikut uraian implementasi budaya Bali dan konsep THK pada Harris Hotel Seminyak:

\subsection{Implementasi Budaya Bali}

Wujud implementasi budaya Bali pada Harris Hotel Seminyak yaitu dengan melaksanakan Peraturan Gubernur Bali Nomor 79 tahun 2018 tentang penggunaan pakaian adat Bali pada setiap hari Kamis, dan hari-hari besar keagamaan Hindu. Staf Harris Hotel Seminyak diwajibkan untuk menggunakan pakaian adat Bali setiap hari Kamis dan hari besar Keagamaan seperti Purnama, Tilem, Galungan dan Kuningan. Pada hari besar keagamaan manajemen Harris Hotel Seminyak juga mengadakan kegiatan-kegiatan berupa lomba busana adat Bali, lomba membuat dekorasi Bali seperti gebogan antar setiap departemen. Setiap Galungan, staf dan manajemen bergotong royong untuk membuat penjor di Padmasana dan di depan pintu masuk Harris Hotel Seminyak, Bali.

Dilihat dari tampilan bangunan, Harris Hotel Seminyak tidak menggunakan ornament khas arsitektur tradisional Bali. Pada interior Harris Hotel Seminyak juga tidak terdapat ornamen maupun dekorasi 
Bali. Hanya terdapat beberapa lukisan dengan gambar aktivitas umat agama Hindu di Bali yang sedang menjalankan persembahyangan, maupun aktivitas sehari-hari. Lukisan tersebut terletak di bagian lobby hotel, kamar dan kamar mandi. Pada restoran, terdapat menu makanan masyarakat Bali seperti Babi Guling, sambal matah.
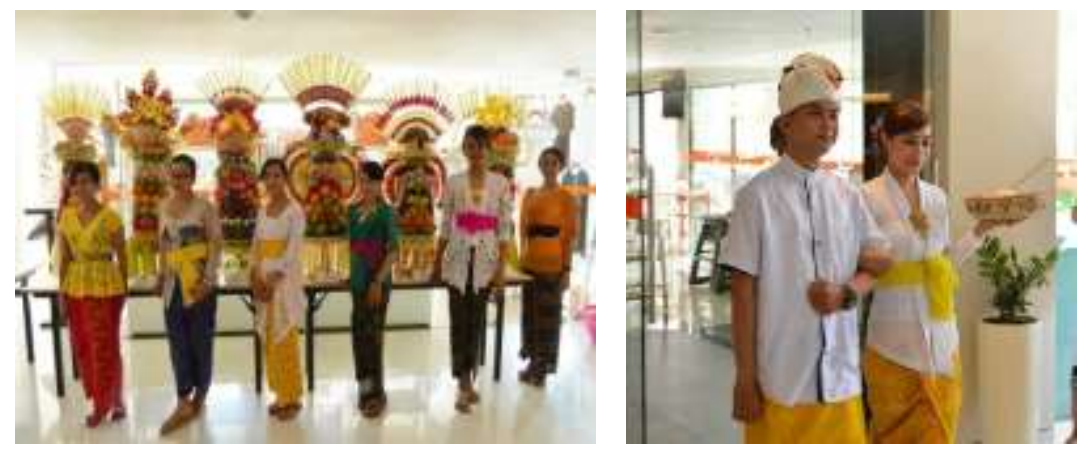

Gambar 2. Penerapan Budaya Bali di Harris Hotel Seminyak Sumber: Manajemen Harris Hotel Seminyak

\subsection{Implementasi Konsep Tri Hita Karana}

Konsep THK terdiri dari parahyangan, pawongan dan palemahan. Parahyangan adalah hubungan antara manusia dengan Ida Sang Hyang Widi Wasa/Brahman sang pencipta/Tuhan Yang Maha Esa. Bentuk implementasi parahyangan yaitu dengan memberikan kebebasan beribadah kepada para staf. Pihak hotel menyediakan beberapa tempat persembahyangan misalnya bagi staf yang beragama Hindu disediakan padmasana untuk tempat persembahyangan. Bagi staf yang beragama muslim disediakan mushola. Pihak hotel juga sangat menghargai dan menghormati kegiatan peribadatan. Pihak hotel tidak menghalangi staf dalam melaksanakan peribadatan atau upacara agama asalkan tidak menganggu pekerjaan. Jika ada staf yang ingin menukar shift atau ijin karena ada upacara keagamaan atau peribadatan, pihak hotel tidak menghalanginya. 
Setiap hari tepatnya setiap pagi terdapat staf yang bertugas untuk menghaturkan canang sari di padmasana dan di setiap section dapartement sebagai bentuk rasa syukur dan memohon keselamatan kepada Tuhan. Walaupun tidak semua staf beragama Hindu, namun Hotel tetap mengisi setiap ruangan dengan pelangkiran. Pihak hotel juga rutin melakukan piodalan di Padmasana Harris Hotel Seminyak serta melakukan tirtayatra ke beberapa Pura di Bali maupun Jawa untuk senantiasa menjaga hubungan yang harmonis dengan Tuhan

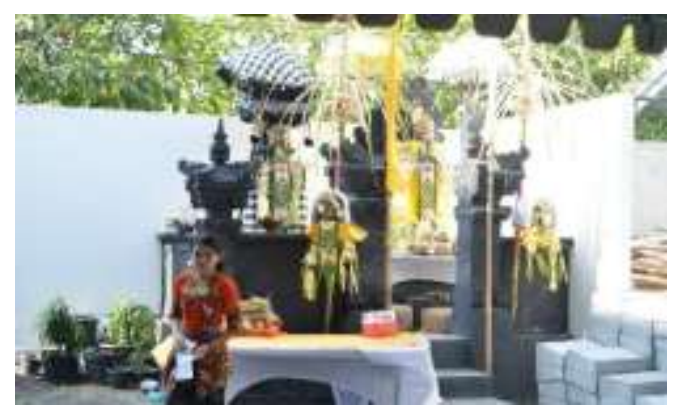

Gambar 3. Penerapan Konsep Parahyangan di Harris Hotel Seminyak Sumber: Manajemen Harris Hotel Seminyak

Pawongan adalah hubungan harmonis antara sesama umat manusia. Wujud implementasi konsep pawongan di Harris Hotel Seminyak yaitu dengan selalu mengadakan komunikasi dan hubungan yang harmonis melalui kegiatan Sima Krama Dharma Santhi/silaturahmi. Kegiatan ini dipandang penting dan strategis mengingat bahwa umat manusia selalu hidup berdampingan dan tidak bisa hidup sendirian. Oleh karena itu tali persahabatan dan persaudaraan harus tetap terjalin dengan baik. A day to share juga merupakan salah satu kegiatan berbagi yang dilakukan oleh Harris Hotel Seminyak, Bali kepada anak-anak yang kurang mampu atau yatim piatu di beberapa panti asuhan di Bali. 


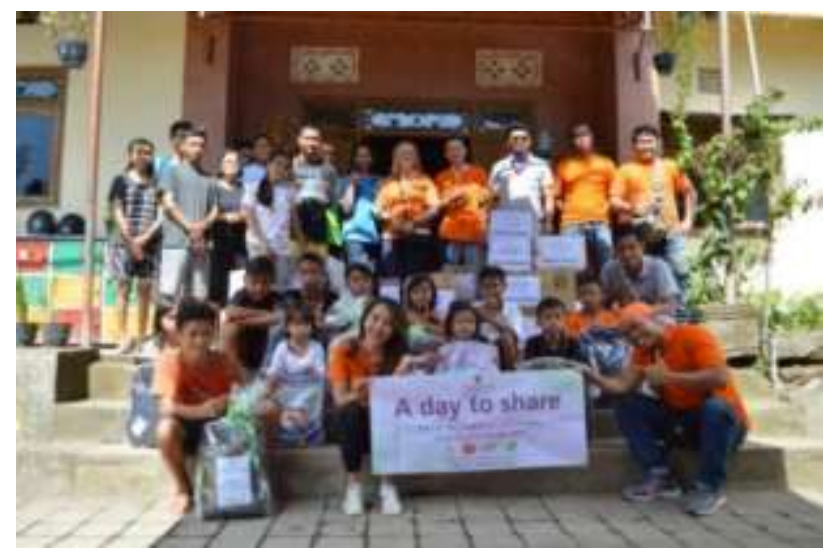

Gambar 4. Penerapan Konsep Pawongan di Harris Hotel Seminyak Sumber: Manajemen Harris Hotel Seminyak

Palemahan adalah hubungan harmonis antara manusia dengan alam lingkungannya. Ajaran ini menekankan kepada manusia untuk tetap menjaga kelestarian lingkungan alam sekitar, sehingga terwujud keharmonisan alam dan tetap terjaganya keseimbangan ekosistem untuk mewujudkan keharmonisan dengan alam lingkungan. Implementasi konsep palemahan diwujudkan dengan rutin memperingati tumpek uduh, tumpek kandang dan mecaru (Bhuta Yadnya) dengan berbagai tingkatannya. Semua konsep itu merupakan suatu tatanan yang mendasar serta mengandung konsep-konsep keseimbangan yang pada intinya memberikan dorongan untuk menumbuh kembangkan rasa cinta kasih kepada sesama dan lingkungan alam. Kegiatan lain dari Harris Hotel Seminyak, yang mengimplementasikan hubungan manusia dengan lingkungan yakni bersih-bersih pantai dan areal desa Seminyak. Para staff ikut berpartisipasi dalam melakukan gotong royong di areal lingkungan desa Seminyak untuk tetap menjaga kebersihan dan menjalin hubungan baik dengan komunitas maupun masyarakat sekitar. 


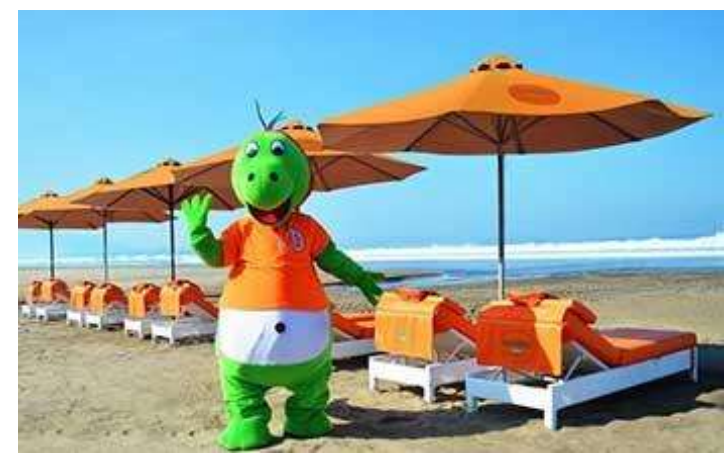

Gambar 5. Penerapan Konsep Palemahan di Harris Hotel Seminyak Sumber: Manajemen Harris Hotel Seminyak

\section{Penutup}

Dari pemaparan tersebut diketahui bahwa Harris Hotel Seminyak telah mengimplementasikan budaya Bali dan konsep THK. Implementasi budaya Bali dan konsep THK sangat perlu diimplementasikan di hotel karana memiliki nilai investasi jangka panjang yang mampu menciptakan loyalitas wisatawan, terjaganya budaya Bali, menciptakan reputasi manajemen, dan terjalinnya hubungan dengan komunitas maupun masyarakat lokal. Sayangnya implementasi budaya Bali dan konsep THK di Harris Hotel Seminyak belum maksimal. Diharapkan kedepannya implementasi budaya Bali dan konsep THK dapat dilaksanakan lebih baik lagi dan kedepan diharapkan Harris Hotel Seminyak dapat mengikuti THK Award karena di dalamnya ada upaya agar tetap menjaga budaya Bali dan menerapkan konsep THK.

Peran pemerintah dalam membuat regulasi bagi setiap pelaku usaha dalam menjalan usahanya di Bali harus dijalankan dengan ketat, sebagai langkah preventif pelestarian budaya Bali. Mulai dari hotel, villa, restoran, industri, travel agent, pedagang sampai kepada konsumennya perlu sama-sama mendukung budaya Bali dan konsep THK tetap terjaga dan terawat dengan baik. Idealnya adalah, jika mendapatkan hasil keuntungan di Bali, sudah sepatutnya wajib pula menjaga alam dan budaya Bali itu sendiri. 


\section{Daftar Pustaka}

Humas BAPPSIK. 2018. Tri Hita Karana Awards Tourism \& Accreditation 2018. Diunduh dari: https://www.warmadewa.ac.id /index.php/baca-berita/885/TRI-HITA-KARANA-AWARDSTOURISM--ACCREDITATION-2018.html

Koentjaraningrat, 2002. Manusia dan Kebudayaan di Indonesia. Jakarta: Penerbit Djambatan

Pujaastawa, I.B.G., 2002. Filosofis Kebudayaan Bali dari Perspektif Antropologi. Materi Penataran Kebudayaan dan Pariwisata untuk Praktisi Pariwisata Bali.

Wiana, I Ketut. 2004. Mengapa Bali disebut Bali ?. Surabaya: Paramita.

Peraturan Daerah No. 5 Tahun 2005 tentang persyaratan arsitektur bangunan yang sesuai dengan prinsip-prinsip arsitektur tradisional Bali

Peraturan Daerah Provinsi Bali nomor 2 tahun 2012 tentang Kepariwisataan Budaya Bali

Peraturan Gubernur Bali Nomor 79 tahun 2018 tentang penggunaan pakaian adat Bali

RTRWP 16 tahun 2009 tentang Nilai-nilai kearifan lokal Bali yang terkait dalam penataan ruang

\section{Profil Penulis}

Dinar Sukma Pramesti, S.T., M.T. adalah Dosen prodi D-IV Manajemen Perhotelan di Politeknik Internasional Bali. Lahir di Denpasar 12 September 1988. Menamatkan Sarjana Teknik Arsitektur di Universitas Udayana pada tahun 2010. Melanjutkan Pendidikan Magister di bidang arsitektur dengan mengambil konsentrasi Arsitektur Kajian Lingkungan Binaan Etnik di Pascasarjana Universitas Udayana yang diselesaikan tahun 2013.

Putu Gilang Adnyani lahir di Kediri, 20 November 1999 adalah mahasiswi program studi D-IV Manajemen perhotelan di Politeknik Internasional Bali Angkatan tahun 2018. 